\title{
ESTUDO COMPARATIVO DE ÓLEOS VEGETAIS NA PREPARAÇÃO DE MICROEMULSÕES UTILIZADAS COMO COLCHÃO LAVADOR
}

\author{
A. G. CABRAL ${ }^{1 *}$, E. A. ARAÚJO' ${ }^{1}$, G. S. LOPES $^{1 *}$, A. I. C. GARNICA ${ }^{1}$, F. D. S. \\ CURBELO $^{1 *}$ \\ ${ }^{1}$ Universidade Federal da Paraíba, Centro de Tecnologia, Departamento de Engenharia \\ Química \\ *email: annagcabral@gmail.com,gustavosantos_lopes@hotmail.com, \\ fabioladias@yahoo.com
}

\begin{abstract}
RESUMO - Durante a etapa de perfuração de poços, fluidos de perfuração são utilizados para remover os detritos gerados. Esses fluidos formam uma película fina nas paredes do poço, chamada de reboco, e que precisa ser removida pelo uso dos colchões lavadores, para uma melhor aderência cimento-formação e cimentorevestimento. As microemulsões são sistemas homogêneos, ternários ou quaternários, compostos pela mistura das fases aquosa e oleosa pelo emprego do tensoativo e, em alguns casos, de um cotensoativo. Esses sistemas têm sido utilizados na formulação de colchões lavadores por apresentarem tensão superficial baixa e boa capacidade na inversão da molhabilidade da rocha reservatório. Este trabalho teve como objetivo o estudo comparativo do desempenho de dois óleos vegetais em microemulsões usadas como colchão lavador. A fase aquosa usada nas microemulsões foi uma mistura de água e glicerina na proporção mássica de 1:1 e o tensoativo não-iônico foi o ultranex NP100. A partir dos diagramas de fases obtidos, 2 sistemas ternários, na região de microemulsão, foram formulados para realizar testes de remoção, turbidez e análise reológica. Esses 2 sistemas foram diferenciados apenas pelo óleo vegetal utilizado (OV1 e OV2). Os resultados obtidos mostraram que o OV1 foi mais eficiente na remoção do fluido de perfuração não-aquoso e mais estável ao aumento da temperatura. Com relação ao estudo reológico, os dois sistemas apresentaram comportamento de fluido newtoniano, avaliados de $30^{\circ} \mathrm{C}$ a $70^{\circ} \mathrm{C}$.
\end{abstract}

\section{INTRODUÇÃO}

Colchão lavadores são fluidos usados na operação de cimentação de poços, deslocados a frente da massa de cimento, e tem a função de remover o fluido de perfuração remanescente nas paredes rochosas, permitindo, dessa forma, uma melhor aderência cimento-formação e cimento-revestimento (Pinheiro, 2013).

As microemulsões são compostas formados por dois líquidos imiscíveis, um espontaneamente disperso no outro, que com o auxílio do tensoativo, ocorre a solubilização destes componentes entre suas moléculas, tornando-o mais estável dentro da estrutura micelar 
do que na solução ou na sua fase original. Esta estabilidade garante a formação espontânea de uma microemulsão (Daltin, 2011). Microemulsões feitas com óleo vegetal e usadas como colchões lavadores tem sido uma fonte de pesquisa promissora, pois, em muitos casos, verificam-se boa remoção e melhora dos parâmetros reológicos do fluido de perfuração e inversão de molhabilidade, o que garante a aderência do cimento. (Quintero, 2015)

O objetivo desse trabalho foi realizar um estudo comparativo de dois óleos vegetais na elaboração de microemulsões para serem utilizadas como colchões lavadores sendo analisados através da remoção de fluido de perfuração, estabilidade térmica e estudo reológico.

\section{METODOLOGIA}

\subsection{Elaboração dos diagramas ternários}

Para a obtenção dos diagramas ternários, foram utilizados dois óleos vegetais (OV1 e OV2) como fase oleosa; um tensoativo não iônico ultranex NP100 (NP100), gentilmente cedido pela Oxiteno; e fase aquosa (FA) composta por água e glicerina na proporção mássica de 1:1.

Para a construção do diagrama, foi utilizado $1 \mathrm{~g}$ de dois dos componentes, com proporções mássicas conhecidas e, em seguida, iniciou-se a titulação com o terceiro componente, até o surgimento de qualquer região, em que a massa do terceiro componente era determinada e, posteriormente, a fração mássica.

\subsection{Teste de eficiência de remoção}

Para a realização do teste de remoção, foram preparados $200 \mathrm{~mL}$ da microemulsão escolhida para análise. A microemulsão foi aquecida sob agitação até a temperatura de teste $\left(88^{\circ} \mathrm{C}\right)$; e o fluido de perfuração não-aquoso, homogeneizado em agitador Hamilton-Beach por cerca de 15 minutos. Imediatamente após o fim da agitação do fluido, verteu-se, no máximo, 4 $\mathrm{mL}$ do fluido de perfuração para o béquer do ensaio, para formar um filme uniforme de reboco, de modo a cobrir toda a superfície da janela de visualização, composta por 66 quadrados, cada um com $1 \mathrm{~cm}^{2}$. Esse último procedimento é feito em no máximo dois minutos. Em seguida, verteu-se, cuidadosamente, o sistema microemulsionado no béquer do ensaio, direcionando-oo para o lado oposto ao da janela de visualização para manter o filme íntegro.

O béquer foi, então, posicionado na plataforma do viscosímetro rotativo (Fann) de forma centralizada e a plataforma elevada para que a base da janela estivesse alinhada à base do rotor. O viscosímetro foi ligado a $300 \mathrm{rpm}$ e, simultaneamente, o cronômetro foi acionado. O teste tem duração máxima de 10 minutos, parando o cronômetro antes, caso todos os quadrados estejam limpos. Por fim, a porcentagem da área limpa em relação à área total da janela de visualização é calculada, sendo, portanto, a eficiência do colchão.

\subsection{Temperatura de turbidez}

O colchão lavador é colocado em um becker sob aquecimento e agitação. A temperatura é medida durante todo procedimento e anotada quando surgir a turbidez do sistema. $\mathrm{O}$ experimento foi iniciado a temperatura de $28{ }^{\circ} \mathrm{C}$, com rampa de aquecimento de $0,1{ }^{\circ} \mathrm{C}$. 


\subsection{Estudo reológico}

Para o estudo reológico das microemulsões obtidas, foi utilizado o reômetro Brookfield DVIII Ultra, spindle CPE52. O reômetro foi acoplado a um banho termostático e a um computador, controlados pelo software Rheocalc 32, no qual foi permitido mensurar a viscosidade das microemulsões no intervalo de temperatura de $30^{\circ} \mathrm{C}$ a $70{ }^{\circ} \mathrm{C}$, variando a cada $10{ }^{\circ} \mathrm{C}$, com precisão de $1{ }^{\circ} \mathrm{C}$. O programa utilizado fornece os valores da viscosidade, tensão de cisalhamento e taxa de deformação. As medidas foram feitas automaticamente a cada temperatura, variando apenas a velocidade de rotação, entre o intervalo de 0 a $100 \mathrm{rpm}$.

\section{RESULTADOS E DISCUSSÃO}

\subsection{Sistemas microemulsionados}

Dois diagramas de fases ternários foram obtidos, conforme mostra a Figura 1.

Figura 1 - Diagramas ternários do sistema: fase aquosa (FA), tensoativo (NP100) e: a) OV1;

b) OV2.

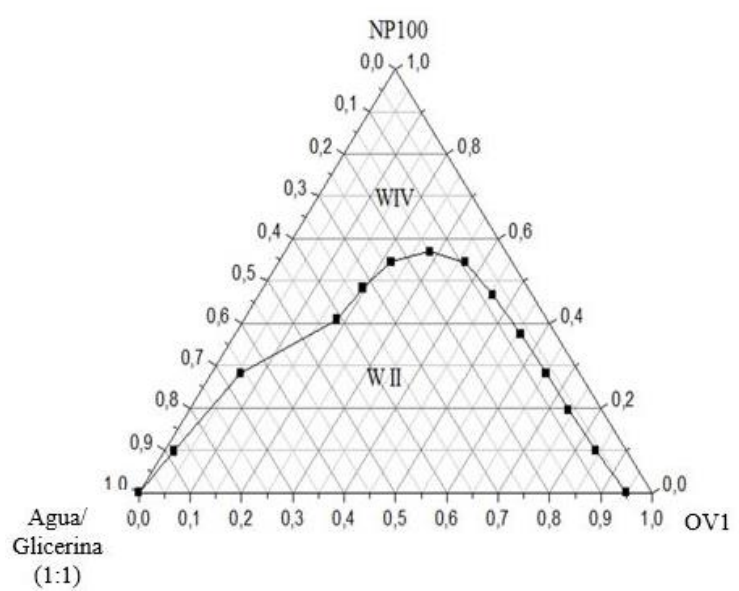

(a)

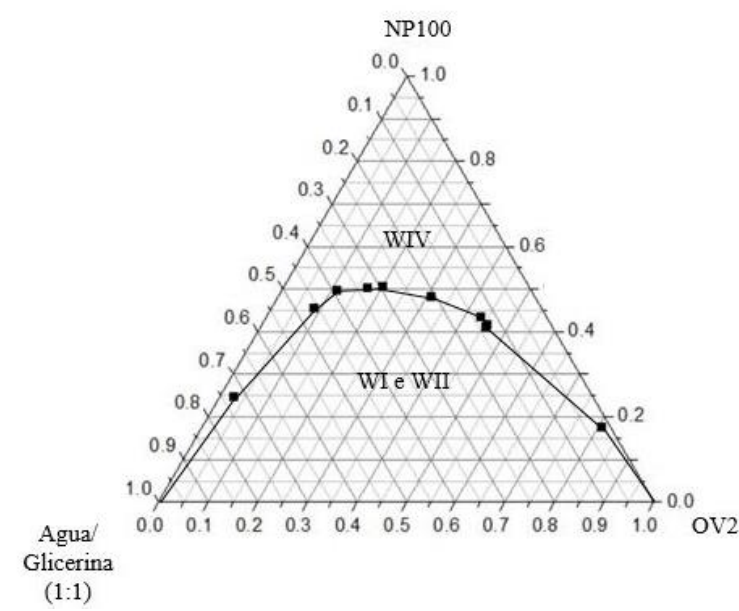

(b)

Nos diagramas mostrados (Figura 1), foram observadas diferentes regiões como: Winsor I (WI), caracterizada pela microemulsão em equilíbrio com a fase oleosa em excesso; Winsor II (WII), microemulsão em equilíbrio com a fase aquosa em excesso; e Winsor IV (WIV) - equilíbrio monofásico de microemulsão (WINSOR, 1968).

Observa-se que a região de WIV do sistema composto pelo OV1 (Figura 1-a) é menor que a do sistema com OV2 (Figura 1-b). Esta diferença pode ser devido ao tensoativo possuir BHL (Balanço hidrofílico-lipofílico) igual a 13,3 (mais solúvel em fase aquosa), uma vez que a escala varia de 0 a 20, em que valores de BHL baixos indicam maior solubilidade em fase orgânica. A composição do OV2 é de, aproximadamente, 40 - 50\% de óleo puro e o restante de ácidos, enquanto que a composição do OV1 é de 95\% de óleo essencial, proporcionando, com isso, uma região de microemulsão maior quando utilizado o OV2. 


\subsection{Seleção do ponto ternário}

Dos diagramas obtidos, foi escolhido o ponto ternário dentro da região de microemulsão (WIV) (Tabela 1), para realizar a comparação dos óleos, da seguinte fração mássica:

Tabela 1 - Pontos escolhidos para realização do teste de remoção, turbidez e estudo reológico.

\begin{tabular}{|c|c|c|c|c|}
\hline Ponto & Microemulsão & $\mathbf{f}_{\mathbf{F O}}$ & $\mathbf{f}_{\mathbf{F A}}$ & $\mathbf{f}_{\mathbf{T}}$ \\
\hline $\mathbf{1}$ & Água e glicerina (1:1), OV1 e NP100 & $40 \%$ & $5 \%$ & $55 \%$ \\
\hline $\mathbf{2}$ & Água e glicerina (1:1), OV2 e NP100 & $40 \%$ & $5 \%$ & $55 \%$ \\
\hline
\end{tabular}

\subsection{Eficiência de remoção e turbidez}

A Tabela 2 mostra os resultados obtidos nos testes de remoção para os pontos $1(\mathrm{OV} 1)$ e 2 (OV2) (Tabela 1).

Tabela 2 - Eficiência de remoção das microemulsões 1 e 2 .

\begin{tabular}{|c|c|c|c|}
\hline Ponto & $\mathbf{N}^{\mathbf{0}}$ de quadrados limpos & Tempo (min) & Eficiência de Remoção \\
\hline $\mathbf{1}$ & 66 & 10 & $96 \%$ \\
\hline $\mathbf{2}$ & 54 & 10 & $81,8 \%$ \\
\hline
\end{tabular}

Percebe-se (Tabela 2) que o sistema microemulsionado composto pelo OV1 é mais eficiente, com $96 \%$ de remoção, do que o sistema com OV2, removendo cerca de $15 \%$ a mais do fluido de perfuração. Tal fato pode ser explicado devido à solubilidade do OV2 em relação ao NP100 ser maior na porção polar. Além disso, o sistema com o OV1 é mais apolar, havendo, então, maior afinidade com o fluido de perfuração não aquoso usado, e melhor remoção.

Com relação à temperatura de turbidez (Tabela 3), percebe-se que o sistema com o OV1 se mantem límpido a maiores temperaturas que o com OV2, com isso, verifica-se uma maior estabilidade das micelas do tensoativo com o OV1, mesmo com maior vibração adquirida pelo aumento da temperatura.

Tabela 3 - Temperatura de turbidez dos pontos 1 e 2.

\begin{tabular}{|c|c|}
\hline Microemulsão & Temperatura de turbidez \\
\hline $\mathbf{1}$ & Não turvou* \\
\hline $\mathbf{2}$ & $42^{\circ} \mathrm{C}$ \\
\hline \multirow{2}{*}{ O sistema foi testado até a temperatura de $118,1^{\circ} \mathrm{C}$} \\
\hline
\end{tabular}




\subsection{Estudo reológico}

O resultado da análise reológica dos pontos 1 e 2 são mostrados na Figuras 3 e 4, respectivamente.

Figura 2 - Análise reológica do colchão lavador com OV1, em diferentes temperaturas

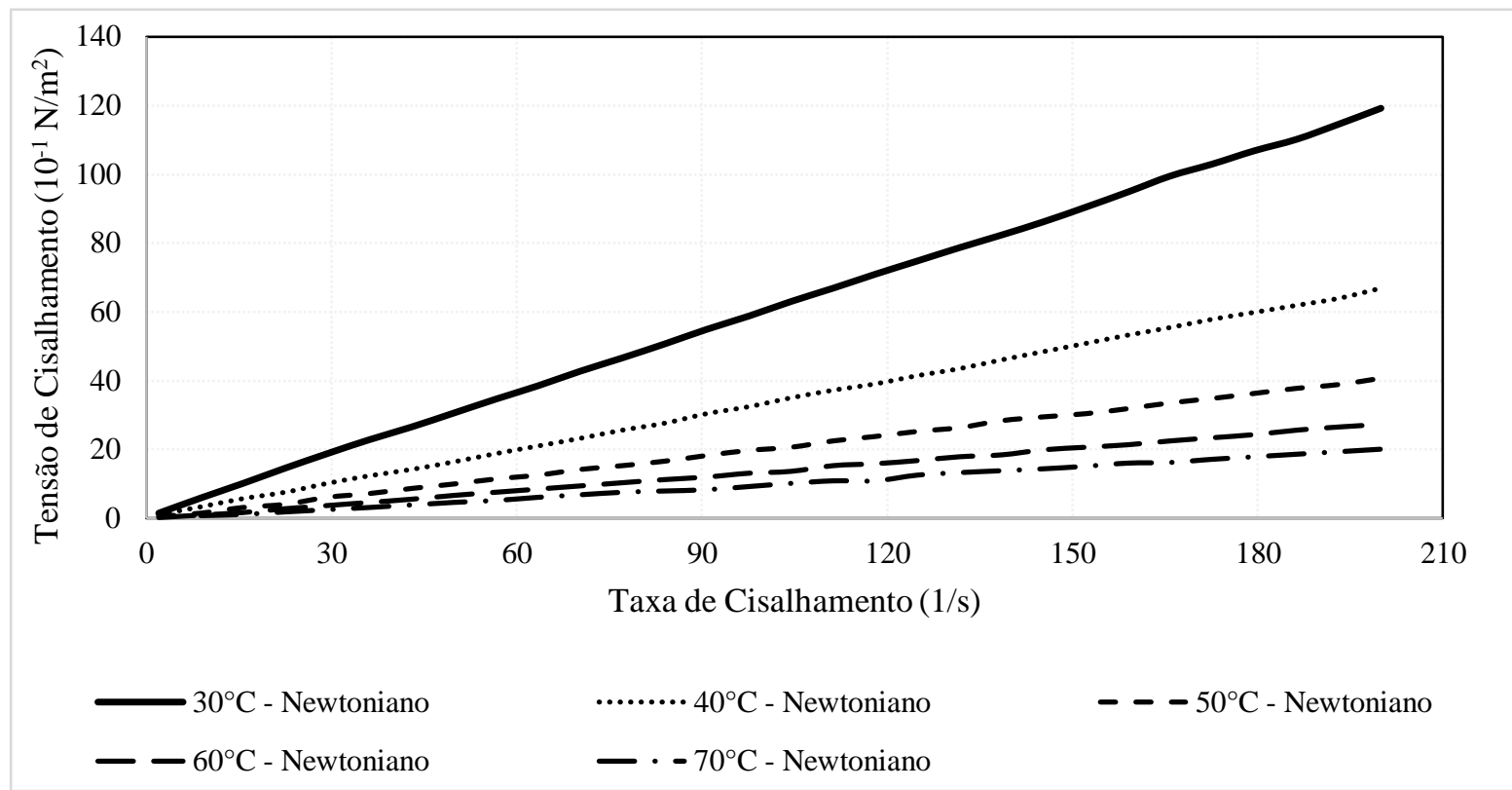

Figura 3 - Análise reológica do colchão lavador com OV2, em diferentes temperaturas.

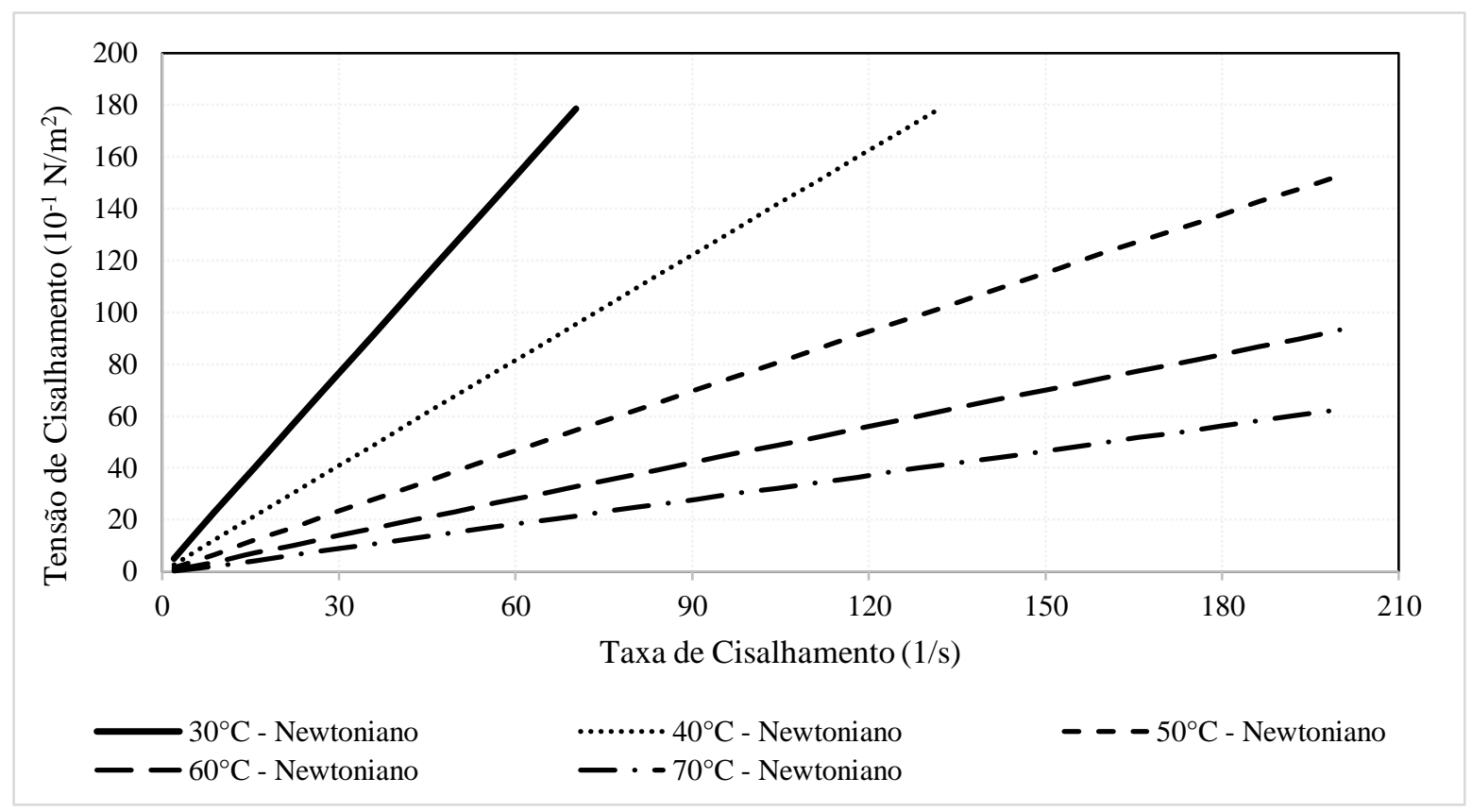


É possível observar que, os sistemas microemulsionados com OV1 e OV2 apresentam taxa de cisalhamento diretamente proporcional a taxa de deformação para todas as temperaturas analisadas, observado pelo comportamento linear dos gráficos mostrados nas Figuras 2 e 3, respectivamente. Sendo assim, estes sistemas podem ser classificados como fluidos newtonianos para todas as temperaturas estudadas. Fluidos newtonianos são os apropriados para utilização como colchões lavadores, já que não é desejado que ocorra variação de viscosidade do fluido, para que haja uma boa remoção do reboco e inversão da molhabilidade da rocha, devido a variação de temperatura e pressão, condições ocorridas ao longo da profundidade do poço. Sendo assim, as microemulsões estudadas são adequadas para serem usados como colchões lavadores, baseados em sua análise reológica.

\section{CONCLUSÕES}

Dois óleos vegetais foram estudados para comporem sistemas microemulsionados utilizados como colchões lavadores de fluidos de perfuração não aquoso. Teste de remoção, temperatura de turbidez e reologia foram realizados para verificar a eficiência de tais sistemas. Os testes de remoção apresentaram bons valores de eficiências, sendo $96 \%$ de remoção para o sistema com OV1 e 81,8\% para o OV2. Estes percentuais indicam que os dois óleos testados nas microemulsões podem ser utilizados nas formulações de colchões lavadores.

O estudo reológico mostrou que os dois sistemas apresentaram comportamento newtoniano para as temperaturas estudadas. Porém, com relação à temperatura de turbidez, a microemulsão com o OV1 mostrou melhor resistência ao aumento da temperatura do que com o OV2, uma vez que este atingiu sua temperatura de turbidez abaixo da temperatura média dos poços de petróleo $\left(55^{\circ} \mathrm{C}\right)$. Com isso, o sistema com OV1 é o mais indicado para uso em sistemas microemulsionados usados como colchões lavadores.

\section{REFERÊNCIAS}

DALTIN, D. Tensoativos: química, propriedades e aplicações, São Paulo: Blucher, 2011.

PINHEIRO, F. Desenvolvimento de Misturas Ternárias Para Remoção de Reboco de Fluido Sintético. Universidade Federal do Rio Grande do Norte (UFRN). Natal, 2013.

QUINTERO, L.; PASSANHA, W.D, HUGHES, B., AUBRY, E., POITRENAUD, H. Advanced Microemulsion Cleaner Fluid Applications in Deepwater Wells. Presented in the Offshore Technology Conference Brasil. 2015.

WINSOR, P. A. Binary and multicomponent solutions of amphiphilic compounds, Chemical Review, v. 68, n. 1, 1968.

\section{AGRADECIMENTOS}

À UFPB e ao CNPq pelo apoio financeiro. 